\title{
Qualimetric Methods in the Evaluation of the Quality of Professional Training of Specialists in Social Work
}

\author{
Natalya Ivanovna Nikitina ${ }^{1}$, Elena Yurievna Romanova ${ }^{1}$, Ekaterina Vladimirovna Komarova ${ }^{1}$, Svetlana \\ Nikolaevna Tolstikova $^{2} \&$ Veronica Mickhailovna Grebennikova ${ }^{3}$ \\ ${ }^{1}$ Russian State Social University, Moscow, Russian Federation \\ ${ }^{2}$ Moscow City Pedagogical University, Moscow, Russian Federation \\ ${ }^{3}$ Kuban State University, Krasnodar, Russian Federation \\ Correspondence: Natalya Ivanovna Nikitina, Faculty of Social Work, Pedagogy and Uvenology, Russian State \\ Social University, Moscow, 129226, Russian Federation. Tel: 8-906-084-3838.
}

This article was prepared in the framework of the state task of Ministry of Education and Science of Russian Federation \#2014/601 (project code 3106).

\author{
Received: December 20, 2014 Accepted: December 30, $2014 \quad$ Online Published: February 25, 2015 \\ doi:10.5539/res.v7n3p66 \\ URL: http://dx.doi.org/10.5539/res.v7n3p66
}

\begin{abstract}
Currently systematic passage social workers training courses and professional training is regarded as one of the necessary conditions for improving their professional competence, professional culture and personal development, as well as enhance their competitiveness in today's job market. In modern Russia the question about the quality of the implementation of training courses and professional training of these specialists had never been more relevant. The article states that the current approaches to the problem provide an objective assessment of the quality of postgraduate professional education professionals social profile is largely based: a) on the basic provisions of the theory of educational measurement, $b$ ) on the basic provisions of the didactic and didactic testology taxonomy, c) to theory of independence procedures of expert assessments; d) on the methods of mathematical statistics; e) The pedagogical paradigm of quality management functioning educational systems, f) on the ideas of standardization of educational processes. The article reveals the essence of qualimetric techniques that the authors for eight years (2006-2014 years) has been successfully used for the objective evaluation of the quality of professional training courses of social work professionals. Particular attention is paid to the application qualimetric methods in the evaluation of the test results of student course preparation. The authors argue that the application of mathematical methods in the system of postgraduate education to assess the level of professional training of trainees help improve the quality of adult learning.
\end{abstract}

Keywords: qualimetry education, professional training, quality management of postgraduate education, professionals in social work

\section{Introduction}

At the present stage of development of postgraduate education social workers, psychologists, social pedagogue question of methods and technologies of assessing the quality of this type of education is one of the most pressing in the scientific and educational research. In connection with this urgent search for new ways to improve the quality of the activities of institutions engaged in training and retraining of specialist social profile. One of these ways is to develop a scientific basis and content-technological basis of the implementation of the system of postgraduate education qualimetric approach.

Since the mid-twentieth century in many countries actively developing qualimetry education (from lat. qualitus - quality, property, dignity, or lat. quolis - "what the quality" and gr. metron-measure or gr. Metreo-measure) as a scientific and applied field implementation of a multi-dimensional assessment of the quality of educational systems at various levels, as well as assessing the quality of personal and professional development of students (Abdullah, 2006; Dimas, Goula, \& Pierrakos, 2011; Richardson, 1998; Subetto, 1993).

Qualimetric approach is an integral component of the theoretical and methodological and scientific and 
technological support the holistic educational process in the system of postgraduate education social workers. This approach focuses on the formation of adult learners (student course preparation, practitioners) required qualification and the required level, taking into account the specifics of the operation of various types of institutions of social infrastructure of modern society. In general, the implementation qualimetric approach in the postgraduate education is designed to standardize levels of attainment of adult learners at the end of a certain stage of learning, i.e., involves comparing the learning outcomes of a particular course participants with a fixed mandatory minimum of assimilation of content postgraduate education with requirements of formation of competence, professionally important qualities of students.

Modern qualimetry of professional education is largely based on: 1) the theory of pedagogical (educational) measurements (e.g., Andrich, 2001; Avanesov et al., 2005; Gulliksen, 1986); 2) methods of mathematical statistics (e.g., Cohen, 1988; Guilford, 1956); 3) didactic testology (e.g., Blinkhorn, 1997; Mikhailychev, 2001) and taxonomy (e.g., Bloom, 1956); 4) on the ideas of standardization of educational processes (e.g., Cizek, 2001; Petersen, Kolen, \& Hoover, 1989); 5) on the theory of independence of the procedures of expert assessments (e.g., Blackmore, 2004). All of the above theories have been used by the authors to develop their own set of qualimetric methods for assessing the quality of professional training of specialists in social work.

\section{Literature Review}

The results of a retrospective analysis of the scientific literature on the problem of assessing the quality of education lead to the conclusion that every era brings its qualimetric paradigm, filling it with their own ideas about the nature and content, object and subject, methods and technologies, and ethical aspects of diagnostic test and measurement and evaluation-productive activity education (Arcaro, 1995; Cheng \& Tam, 1997; Colling \& Harvey, 1995; Ehlers, 2009; Safontsev, 2004; Subetto \& Selezneva, 1999).

To identify the current level of education qualimetry the authors examined research papers on different issues of quality control of school education (Fomina, 2011; Miller \& Rowan, 2006), Higher Professional Education (Bellingham, 2008; Brenna \& Shah, 2000; Fraser, 1994; Green, 1994; Harvey \& Williams, 2010; Srikanthan \& Dalrymple, 2003) and post-graduate education (Angell, Heffernan, \& Megicks, 2008; Bitusikova et al., 2010; Faber, López, \& Prescher, 2012; Galkina \& Nikitina, 2014).

It should be noted that in recent years published many scientific research in the field of quality control of higher education engineering profile (e.g., Borrego, Douglas, \& Amelink, 2009; Garafutdinova, 2011; Owlia \& Aspinwall, 1998; Shikhov, 2008) and economics (e.g., Borges, Santos, \& Leal, 2014; Soutar \& McNeil, 1996; Medvedeva, 2009). This can be explained by the fact that the essence of the quality of professional training of graduates of these profiles can be clearly parameterized (diagnosed develop a clear hierarchy of professional skills, competencies, etc.), and then quite objectively assessed by a specially designed measuring control and evaluation methods.

According to the authors, to date, not enough research to develop qualimetric learner-centered tools for assessing the quality of postgraduate education specialists "helping" professions-specific content and technology for their professional work in modern conditions.

In the Russian science theoretical justification qualimetric tools for a system of professional retraining social workers associated with certain difficulties. Some of the difficulties associated with current tensions between supporters and opponents of the introduction of mathematical methods in teaching vocational training specialists socio-humanitarian profile. Opponents believe that it is impossible to measure the high degree of objectivity in the graduates (with a degree in "Social work" or "Social pedagogy") the level of development of professional competence, quality of professionalism. All this can be more or less well defined by experts (among them the heads of social service, which employs graduate, skilled practitioners, university professors social profile, a social service clients) only as a result of self-employment of young specialists (at the end of the year since the end of high school). This position is related to the fact that in the professional training of young professional social and humanities too much personality components, which are formed mainly in self-employment and are due to the individual characteristics of its professionally important qualities.

Meanwhile, the number of works (Subetto \& Selezneva, 1999; Sviridov, 1981) clearly demonstrate that qualimetric methods (developed on the basis of mathematical theories) can be applied in educational practice for a sufficiently objective assessment of results of a complex process of professional and personal development of training programs graduates (at college, university) and professional retraining (in the system of postgraduate education) specialists socio-humanitarian profile.

However, today in Russia there is still not enough researches in the field of qualimetry of postgraduate training 
of specialists in the field of social work. This is a little due to the fact that the profession "social work specialist" itself is considered in Russia to be "young" (April 23, 1991 in the all-Russian classifier of professions new specialties were officially registered: a social worker, a social pedagogue and a specialist in the field of social work). Over the years, the development of the profession in the Russian scientific research in priorities was other questions of formation of system of continuous professional education of these specialists.

In this article, the term "quality of professional retraining of social work specialists" is understood as: 1) the degree of "suitability" of the graduate courses (in Russia it is a program of professional retraining of over 500 hours) to efficient and highly qualified performance of professional activities in accordance with the labour functionality; 2) the degree of satisfaction the adult learners' vocational educational requirements (needs), his employer and professional community as a whole.

\section{Methods and Data}

Presented in this work qualimetric methods were used in the period from 2006 to 2014 to control the quality of training and professional process in each of the study groups of professional retraining courses for social work specialists program "Manager institutions of social protection and social services" (508 hours).

These courses were held at Russian State Social University (Moscow) and its branches in the cities of Kursk, Sochi, Anapa. The training was based on the same curriculum, standardized syllabus, unified teaching materials. For the verification of knowledge, skills of adult learners a single complex of test, control and measuring materials were used.

In each training group, there were 30 students (practitioners). There were 3 studying groups at the same time. Total number of all adults enrolled in the retraining courses (all of them voluntarily participated in the experimental work) was 2880 people. Age adult learners in each group were 25 to 55 years. The average age of students in each individual group was 38 years. In all groups was approximately $72 \%$ female and $28 \%$ male.

All students in the professional courses have had higher professional education $(28 \%$-in the field of pedagogical profile, $26 \%$ - on a specialty "Social work", $16 \%$ - on a specialty "Psychology", $14 \%$ - on medical specialties, $11 \%$-in the field of engineering and economics, $5 \%$ - had military education). However, in Russia for administrative work in an institution of social profile (social service centers, centers for social assistance to families and children, the Center for Social Gerontology, et al.). Requires retraining program "Manager of institutions of social protection and social services" (508 hours). Each group was trained according to the curriculum during the school year (from September 01 to 01 of July). The training took place without interruption from work (contact for classroom training sessions with teachers were carried out on Saturdays and 1 every weekday in the evening).

\section{Results}

\subsection{Design of a Mathematical Model of the Process Kvalitativizatsii Postgraduate Education}

To build a mathematical model of the process of qualitatively postgraduate education was applied the "problem-trajectory description of theoretical material" method in the process of program-target modeling (Pospelov \& Irikov, 1976). In accordance with this methodology, each problem is characterized by a certain set of result indicators $\left(R P_{1}, R P_{2} \ldots R P_{n}\right)$, which reflect objectively its status at any time $t$. In our case, the resulting indicators of the quality of professional retraining are formed necessary professional students' competence (PC) and professionally important qualities (PIQ) of a specialist in strict accordance with the functional qualification requirements and the objective demands of modern labour market and employers. Therefore, the problem of mathematization of qualimetric approach $\left(P_{M Q A}\right)$ in the system of postgraduate education $P_{M Q A}$ can be

represented as a tuple: $P_{M Q A}=\langle O R, R I, I s, D s\rangle$, where $O R$ is the object of research (in our case, the development process in terms of professional competences training and PIQ of a specialist); $R I$ is the result indicator characterizing the state of $O R$; Is is the initial state of $O R$; $D s$ is the desired state of $O R$. Thus, the mathematical formulation of the problem has the form: $P_{M O A}=\|R I-D s\| \rightarrow 0$ (1). This means: it is necessary to eliminate the discrepancy between the desired $D s=\left(D_{s_{1}}, D_{s_{2}}, \ldots, D_{s_{N}}\right)$ and the current 
$\left(R I_{s_{1}}, R I_{s_{2}}, \ldots, R I_{s_{N}}\right)$ state of the object of research.

There are several ways to solve the above problem. In particular, it is possible to implement the model of Joseph Juran (1988), which describes a spiral-shaped continuous development and improvement of quality (in our case, the improvement of quality of additional professional educational services in the field of professional retraining).

Returning to the formula (1), note that in the studied case, the state of the object of study (the original status of all subsystems of a training course: the training, personnel, logistical and other) depends on controllable factors, which include:

1) Level of professionalism, professional competence and culture of trainers of the courses.

2) Systematic, purposeful and appropriate correction of substantive and methodological basis of the courses (curricula, working programs).

3) Vocational educational technology of teaching adult students (practitioners) correspondence to modern didactic and andragogical requirements.

4) Systematic and purposeful increase of level of logistical and staffing of educational process.

We emphasize the fact that at the input to the system implementation process course there are factors potentially manageable (as described above), and unmanaged. By uncontrollable factors may include the following items:

1) Different levels of general education and general professional performance preparedness course participants in the learning process.

2) The level of the health status of adult learners, which in varying degrees, affect the quality of assimilation of training material for the formation of new or development of existing professional competencies.

3) The level of conflicts of individual moments of andragogic interaction in systems "a teacher-a student of courses", "a teacher-a group of students" (e.g., the conflict of individual styles of learning activities of students and individual style of teaching), "a course student - a group of students", "a course student-leaders of internship".

Drawing on the work of several researchers (Mechkov 2005; Komarova \& Nikitina, 2014), we propose the following interpretation of mathematization of qualimetric approach in the postgraduate education of social workers.

Let's take a group of courses of professional retraining (e.g., "Manager of institutions of social protection and social services" $(508 \mathrm{~h})$ or the program "Management organization to provide rehabilitation services to people with disabilities" $(508 \mathrm{~h})$ ), which is characterized in the point of time $t$ by a certain degree of uncertainty of knowledge (the students) about the subject, e.g. the entropy $S(t)$.

Let's denote by $H(t)$ the information which is somehow connected with the subject of study (e.g., program-educational information about modern technology of providing social and psychological assistance to clients of social services, technology, occupational therapy). This information comes to the group of students from teachers, as well as from specialized literature and the Internet sources, from other group members (practitioners) who have some experience in this field, from specialist institutions, which are databases and internships for trainees, etc.

This information is highlighted, on the one hand, the information that reduces the entropy, that is, one way or another in order, organizes knowledge of adult learners (trainees) the subject matter, and, on the other hand, we select the information that for one or other reasons for studying is "excessive" (e.g., information could "outdated", in particular, changes in the legal framework of social services to the population, in the field of medical hardware technician rehabilitation clients of social services, and others.).

Changing the amount of information $\Delta H(t)$ per time $\Delta t$ is equal to $\Delta H(t)=-\rho_{1} \cdot S(t) \cdot \Delta \mathrm{t}+\rho_{2} \cdot H(t) \cdot \Delta \mathrm{t}$,

where $-\rho_{1} \cdot S(t)$ and $+\rho_{2} \cdot H(t)$ respectively are the information flows of the first and the second type.

Writing down this equation in the differential form, we obtain for $H(t) \frac{d H(t)}{d t}=-\rho_{1} \cdot S(t)+\rho_{2} \cdot H(t)$, and 
the balance of entropy flow $S(t)$ in this case corresponds to the equation: $\frac{d S(t)}{d t}=-\mu_{1} \cdot S(t) \cdot H(t)-\mu_{2} \cdot S^{2}(t) \cdot H(t)+\alpha \cdot S^{2}(t)+\beta \cdot H(t)+\gamma \cdot S(t)$, where $-\mu_{1} \cdot S(t) \cdot H(t)$

is the decrease of entropy as a result of interaction of students with regular, systematic, corresponding to the modern level of development of science and professional practice information they receive in the process of classroom studying, as well as in the self-study process of quality and specialized manuals that are developed by highly qualified teachers in conjunction with practitioners internship (It should be noted that the quality of the content, methods, assessment tasks, textbooks for students of a course of training can be measured by a specially developed criteria based on a scale from 0 to 1$),-\mu_{2} \cdot S^{2}(t) \cdot H(t)$ is the decrease in entropy due to an interactive discussion adult learners received their systematic, scientific-theoretical and professional application of information in the process of classroom seminars, workshops, as well as the decrease in entropy due to the use of highly qualified teachers during seminars optimally effective professional and educational technologies of adult learning: design technology, case-tech, technology contextual learning, gaming technologies (it should be stressed that the quality of the implementation of vocational and adult education educational technology in the course of preparation can be measured by a specially developed criterion based on a scale from 0 to 1); $\alpha \cdot S^{2}(t)$ is the increase of entropy, which is due to constructive-information contacts adult learners together in extracurricular time (e.g., the Internet, when one of the other trainees sends false information to perform independent work) or in periods of practice, if the process is not practical training organized by the quality and not adequately controlled leaders, methodists practice (e.g., when filling out diaries practice trainees incorrectly interpreted, from a theoretical point of view, the behavior of the client's social service, put the wrong social, psychological diagnosis given client, and Methodists, curator practices of institutions, and teachers courses in the classroom where they discussed the results of practice, did not pay for one reason or another account on this false information, we note that the number of adult learners internalized false information can be measured by a specially developed criterion based on a scale from 0 to 1$), \beta \cdot H(t)$ is the increase of entropy, which is associated with independent contacts of students with unreliable or needed information (e.g., doing independent tasks, writing essays, term papers adult students can use a certain amount of inaccurate information obtained from the Internet sources; there may be cases receiving inaccurate information, and in periods of practice, training from incompetent professionals of bases of practice; the number learned unreliable information by adult learners can be measured by a specially developed criteria based on a scale from 0 to 1$), \gamma \cdot S(t)$ is the increase of entropy in those periods when adult student for one reason or another didn't learn the training material (e.g.,was ill, did not have access to the Internet to learn the material, etc.). As a result, to determine dependencies $H(t)$ and $S(t)$ we obtain a system of nonlinear differential equations: 


$$
\left\{\begin{array}{l}
\frac{d H(t)}{d t}=-\rho_{1} \cdot S(t)+\rho_{2} \cdot H(t) \\
\frac{d S(t)}{d t}=-\mu_{1} \cdot S(t) \cdot H(t)-\mu_{2} \cdot S^{2}(t) \cdot H(t)+\alpha \cdot S^{2}(t)+\beta \cdot H(t)+\gamma \cdot S(t) .
\end{array}\right.
$$

This system is in this field of function changes $(H \geq 0, S \geq 0)$ and in the absence of control (i.e., if the system parameters, or coefficients are constant in time) has two equilibrium points: the trivial $H_{0_{1}}=0, S_{0_{1}}=0$ and $H_{0_{2}}=\frac{\rho_{1}}{\rho_{2}} S_{0_{2}}, \quad S_{0_{2}}=\frac{-\left(\mu_{1} q-\alpha\right)+\sqrt{\left(\mu_{1} q-\alpha\right)^{2}+4 \mu_{2} q(\beta q+\lambda)}}{2 \mu_{2} q}, \quad q=\frac{\rho_{1}}{\rho_{2}} \quad$.The $\quad$ calculations obtained show that at constant parameters of the system:

a) If at the initial moment of time the parameters are such that the state of the system corresponds to one of the equilibrium points, then the system will maintain this state in the absence of impacts.

b) If at the initial moment $H>H_{0_{2}}$, then under $t \rightarrow \infty$ the function $H \rightarrow \infty$ and the entropy $S$ asymptotically tends to zero.

c) If $H(0)<H_{0_{2}}$, the entropy of the system increases indefinitely, and the level of $H(t)$, on the contrary, decreases.

However, changing the time parameters of the system (Figure 1 and Figure 2) you can change the behavior of functions $H(t)$ and $S(t)$.

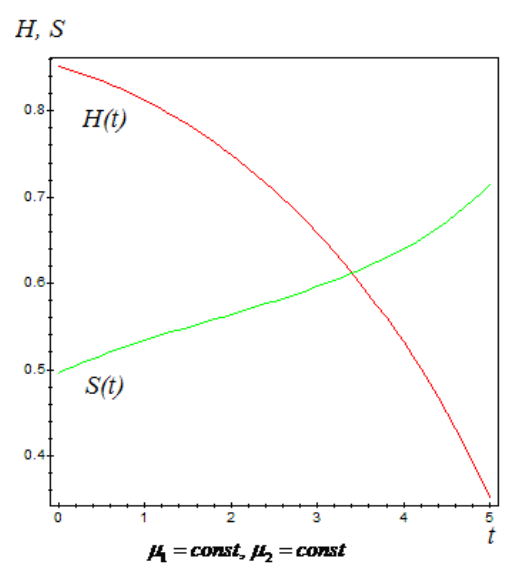

Figure 1 . State quality professional retraining courses at constant parameters 


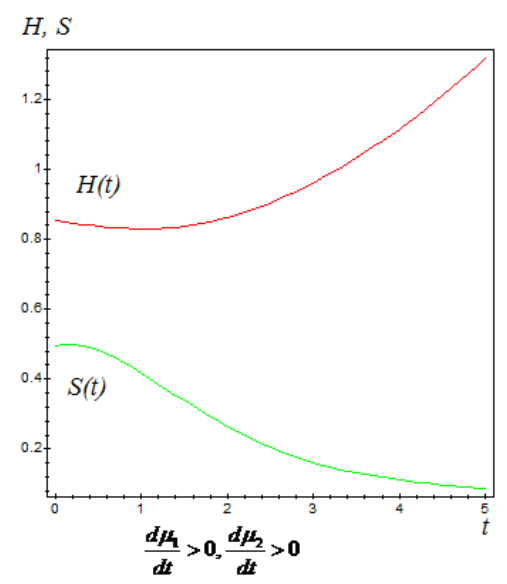

Figure 2. State quality professional retraining courses at measured time parameters

Thus, analyzing the resulting system, we can say that one of the main goals of the educational process of retraining courses is to develop such administrative decisions, which would be aimed at strengthening the influence in those equations members who are responsible for the decrease in entropy, and to reduce the role of members responsible for its growth. However, if purposefully and systematically improve scientific and professional theoretical and applied content of educational content retraining courses on the basis of interdisciplinary connections, it is possible to some extent affect those members who are responsible, as for the decrease in entropy, and unfortunately, for the increase of entropy (e.g., overload adult learners unnecessary theoretical information that is significant enough or not significant for their professional activity).

With didactically and andragogically correct approach to the planning and organization of educational process in the system of professional retraining it is important to actively promote the role of the members responsible for the reduction of entropy (e.g., the development of students required professionally relevant information resulting from the application of case-technologies, collective training solutions professional-application tasks in the course of the workshops, business games, complete individual and group projects).

\subsection{Application Qualimetric Methods to Evaluate the Test Results of Students Course Preparation (Particularly Effective Application Qualimetric Methods for Assessing the Results of Testing Trainees Tetraining)}

In our opinion, based on the analysis of objective data about the intermediate values of the assessments of the quality of training in the system of postgraduate education, calculated between the conduct of the individual measurement and control tests (e.g., a series of tests on specific topics, topics of discipline, a number of practical work on the formation of specific skills, competencies), possibly based on qualimetric analysis to predict the outcome (final) value assessments of learning outcomes trainees planning process at the same time the adjustment work to eliminate certain gaps in the system generated knowledge, skills, competencies in individual adult learners.

Based on the study of a number of works in the field of quality control of education (e.g., Krasnov, Girov, \& Krasnov, 2006; Nikitina, Galkina, \& Komarova, 2013), as well as on the basis of generalization of their own scientific research the following qualimetric model for quality assessment courses of professional training was designed, which is a hierarchically organized system of gradual assimilation of learners evaluation in specific fields of knowledge (academic disciplines course schedule).

Assessing the quality of students assimilation some basic (atomic) knowledge fields are found by comparing the actual values obtained by diagnostic measurements (e.g., by comparison with standard regulatory baseline values). Assessing the quality of assimilation component knowledge fields are calculated based on estimates of their subordinate simple properties.

In the process of qualimetric evaluation of the knowledge hierarchy of knowledge is formed taxonomic division of the whole subject field of knowledge of the sections, then the sections of private topics, etc., up to the elementary components of knowledge systems (basic concepts, definitions, categories, etc.), the corresponding basic (atomic) fields of knowledge.

To determine the results of tests of level of the assimilation each atomic field of knowledge (usually binary value assessment: 1 —elementary component assimilated, 0 -not assimilated) developed one or more tests. 
Calculation of final quality assessment of assimilation knowledge systems (QS) is produced at the end of each test, so a lot of the calculated intermediate results is considered as a static system. If during the course of training programs it is objectively necessary to reduce the number of control and measurement tests based on the data analysis qualimetric forecasting final assessments of students it should conduct a preliminary assessment in the calculation of the intermediate tests. In this case the set of assessments changes after each test, i.e., this is a discrete dynamical system.

It is to be noted that intermediary test results among adults are not very reliable: the less frequently tests were conducted, the more presumptive (calculated beforehand) final results in the end of the whole course can deviate from the real ones. Therefore, for a more complete description of the system of state assessments, in addition to estimates of QS, it is advisable to set this parameter as reliability (objectivity) assessments (prior to testing this parameter is set to 0 , and then increases monotonically to 1 by the end of all trials). In this case, a qualitative model for the assessment of quality courses allows you to consider the dynamics of changes of values (numeric score), and reliability estimates. The proposed model is based on the combination of formal theory of graphs and theory non-axiom logic, which are frequently used in different sections of qualimetry (including qualimetry of education).

The basis of qualimetric model for assessing the quality of education is oriented acyclic graph $G$ with a single sink (Figure 3), which specifies a hierarchy in the quality evaluation system of knowledge QS. Each vertex corresponds to their field of expertise. The digraph $\mathrm{G}$ is the Hasse diagram of the partial order (greatest element) fields on the incorporation of knowledge into each other. The entire learning material corresponds to the greatest element (sink). Each of the minima (sources) corresponds to some relatively small field of knowledge that testing should be tested by one test task.

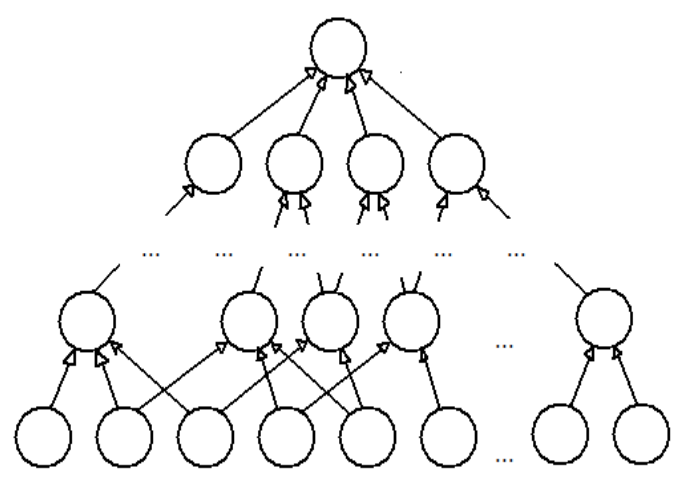

Figure 3. Count hierarchical quality assessment system of knowledge with a single drain

Of course, for each test there are different ways to define the hierarchy of fields of knowledge, the exploration of which is checked by testing. However, for the purposes of qualimetry it is much easier to develop several tests for fixed hierarchy of fields of knowledge, and then to carry out different test in the same group of students at different stages of training (e.g., in the final test on the subject and written exam) and repeat this procedure (possibly with modifications of tasks) for each new intake of students. This will standardize the handling of test results and to study the impact of different factors (primary level students, use when learning different teaching methods, etc.) on studying results.

Note also that it is desirable that the partial order of the fields was ranked, that is, the lengths of all (maximal by inclusion) oriented paths to a fixed vertix, are equal. This, however, does not necessarily, in any case, one of the metric characteristics of vertex $V_{j}$ in the acyclic digraph is its depth $d\left(V_{i}\right)$, that is, the maximal length of the oriented path to $V_{j}$. It is clear that each arc in the acyclic digraph leads from the vertex of the smaller depth to the vertex of the greater depth.

The set of vertices $V$ of the digraph $G$ consists of three disjoint subsets: sources $B$, the only sink of the digraph $I$, all other (intermediate) nodes of graph $P$.

In the graph $G$ there is an $\operatorname{arc}\left(V_{i}, V_{j}\right)$ if and only if the field of knowledge that corresponds to the vertex $V_{i}$ is strictly contained in the field of knowledge corresponding to the vertex $V_{j}$, but in the hierarchy, there is no field of knowledge, strictly containing a field of of knowledge for $V_{i}$ and strictly contained in the field for $V_{j}$. Every 
vertex $V_{i}$ of the sets $P$, $I$ correspond to those and only those test items, for each of which there is an oriented path from the corresponding test set source $V_{i}$ to vertex $V_{j}$.

Each vertex $V_{i}$ of the graph (by induction over the depth of the vertex) is mapped to a positive weight $w\left(V_{i}\right)$ as follows. For the source $V_{i}$ its weight $w\left(V_{i}\right)$ is equal to the maximum score for the corresponding source test task (for simplicity, we can assume that this value is 1 ).

Let for any vertex of depth smaller then $d$ ( $d$ is a natural number) the weight is already defined. Let us consider an arbitrary vertex $V_{i}$ of depth $d\left(V_{i}\right)=d$. The weight $w\left(V_{i}\right)$ of this vertex is defined as the sum of weights of all vertices which have an arc to $V_{i}$.

Each student (let's take, e.g., student $N$ ) is mapped to a separate copy of the digraph $G$, additional marking of vertices which are the results of testing. These additional notes are defined. The test results for each student $N$ and for each vertex $V_{i}$ is defined assessment $w^{+}\left(N, V_{i}\right)$. For the source $V_{i}$ assessment $w^{+}\left(N, V_{i}\right)$ is equal to the assessment of student $N$ corresponding to this source test task (for simplicity, we can assume that this value is equal to 0 or 1 ).

Let for all vertices of depth smaller then $d$ ( $d$ is a natural number), the estimation of $w^{+}\left(N, V_{i}\right)$ is already defined. Consider an arbitrary vertex $V_{i}$ of depth $\left.d\left(V_{i}\right)\right)=d$. Assessment $w^{+}\left(N, V_{i}\right)$ of this vertex is defined as the sum of the estimates $w^{+}\left(N, V_{i}\right)$ for all vertices $V_{i}$, which have an arc to $V_{i}$. In addition, for each vertex $V_{i}$ by the degree of assimilation of the material is determined as: $Q\left(N, V_{j}\right)=\frac{w^{+}\left(N, V_{j}\right)}{w\left(V_{j}\right)}$. Note that degree of assimilation of the material calculated thus the for different vertices can take values from different sets of rational numbers of the segment [0;1], and this is not always convenient. So one can split the interval $[0 ; 1]$ into disjoint intervals (according to some criteria), to enumerate the intervals in ascending order, starting from zero, and to reassign the value of $Q\left(N, V_{j}\right)$ as the number of interval in which it appeared. Values $Q\left(N, V_{j}\right)$ are the primary material for qualitative assessment.

The results of test attended by $N^{*}$ students can be indicated by a table (matrix) $M$ size $N^{*} \times|V|$, the rows of which correspond to the listeners, and the columns correspond to the vertices of the graph $G$. The intersection of line $N\left(1 \leq N \leq N^{*}\right)$ and column $i(1 \leq i \leq|V|)$ in the table contains the value of $Q\left(N, V_{i}\right)$. We will denote the $N$-th row of the matrix $M$ by $M_{N}$, and the $i$-th column by $M^{i}$.

In the first phase of qualitative assessment for each column $i(1 \leq i \leq|V|)$ the mathematical expectation and the variance of the values in this column are calculated. These values are important statistical characteristics of degree of assimilation of the relevant fields of knowledge.

Then in the proposed hierarchy a comparison of degrees of different fields assimilation is carring on. Let's say that column $M^{i^{\prime}}$ precedes the column $M^{i \prime \prime}$, if for each $N\left(1 \leq N \leq N^{*}\right) N$-th component of column $M^{i^{\prime}}$ does not exceed $N$-th component of the column $M^{i,}$, i.e., $Q\left(N, V_{i^{\prime}}\right) \leq Q\left(N, V_{i^{\prime}}{ }^{\prime \prime}\right)$.

Divide the columns of the table $M$ into equivalence classes by equality of columns. Build (in according with the table $M$ ) a new table $M^{\prime}$ ' without equal columns so that each column of $M$ would be equal to the column in $M^{\prime}$, and there are not columns not equal to the columns of $M$. Then each column of $M^{\prime}$ corresponds to the equivalence class (by equality of columns) in $M$. The precedence relation on the set of columns of $M^{\prime}$ ' is a partial order. The Hasse diagram of this partial order visualises the comparison of learning (by all students) of the fields in the specified hierarchy.

Serial testing of one group of listeners, obviously, will help someone to detect the progress in the assimilation of knowledge at individual and group level.

In the next step it is necessary to divide students into classes with a some fairly close characteristics associated with a table $M$ values or sets of such values. These values may be the degree of assimilation of the entire subject field by students, the arithmetic average of the assimilation degrees of some or all fields of knowledge (e.g., the average of assimilation degrees of all fields of hierarchy with fixed depth (in $G$ )). It is possible to divide rows in $M$ ' into disjoint classes, assuming that within each class there are only rows such that for each pair of rows is some metric (e.g., the sum of the absolute values of the differences between same components of these two rows) does not exceed a predetermined threshold. This partitioning can be done in many ways, the selection of clustering algorithm is one of the key stages in the task of classification in the theory of pattern recognition. However, for aims of qualimetry it is better to suggest that a method of separation into classes is a priori fixed. 
For each class one can count the number of its students and calculate for each field and for each class the average and the variance of degree of assimilation of this field of knowledge by the students of this class. The accumulated observations of the changes of these values will allow to make conclusions about the effectiveness and versatility of the used teaching methods. Moreover, these observations will allow one to make predictions of the degree of assimilation of the material by students.

The proposed model of quality retraining assessment allows to take into account the dynamics of changes in the quality of assessment process in a series of diagnostic tests. This model forms the basis for forecasting of the final estimates based on the intermediate values.

\subsection{The Results of Applying the Mode}

There were tested $N=200$ students. According to the test results the classes capacities were formed: $\left|A_{0}\right|=40,\left|A_{l}\right|$ $=119,\left|A_{2}\right|=35,\left|A_{3}\right|=8$.

The model inputs: $\mathrm{P}_{01}^{0}=0.23, \mathrm{P}^{0}{ }_{11}=0.72, \mathrm{P}^{0}{ }_{12}=0.09, \mathrm{P}^{0}{ }_{21}=0.57, \mathrm{P}^{0}{ }_{22}=0.43, \mathrm{P}_{31}^{0}=0.75, \mathrm{P}^{0}{ }_{32}=0.25, \mathrm{P}^{0}{ }_{00}=0.77$, $\mathrm{P}^{0}{ }_{13}=0.05, \mathrm{P}^{0}{ }_{10}=0.14 ; \delta_{11}=0.32, \delta_{12}=0.36, \delta_{13}=0.62, \delta_{21}=0.24, \delta_{22}=0.78, \delta_{23}=0.18, \delta_{31}=0.4, \delta_{32}=0.26, \delta_{33}=$ 0.1 .

Calculations based on the model do not require special mathematical training and can be performed using, e.g., built-in tools of MS Office Excel.

As a result of application of the model, the following optimal solution is obtained:

1) For students of class $A_{1}: y_{13}=1$, it was recommended to carry out design tasks (individually or in small groups on the subject, which is determined by the teacher based on the data from test).

2) For students of class $A_{2}: y_{22}=0.95, y_{23}=0.05$, it was recommended to work out practical examples and get acquainted with cases in which the above procedure permits the professional tasks of a particular class.

3) For students of class $A_{3}: y_{31}=0.52, y_{32}=0.48$, it was recommended to repeat the whole theoretical material and do typical practical examples (learn the algorithms for their solution), with approximately equal time to both work.

Number of classes according to the test results $\left(N^{t}\right)$, the forecast population in the presence of $\left(N^{+}\right)$and absence $(N)$ actions (recommendations) are presented in the chart and classified in the re-testing of students $\left(N^{t+1}\right)$ are presented in Figure 4.

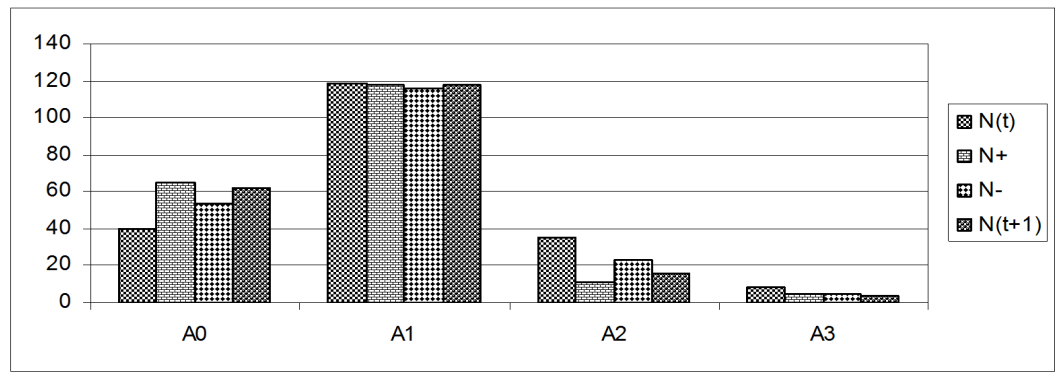

Figure 4. The results of applying qualimetric model to testing procedure for retraining programs

Retest showed an increase in the general level of training at $10.5 \%$ while the forecasted $12 \%$ in the case of implementation of the recommendations, and 5\% in the absence of focused self-study course participants.

\section{Discussion}

Presented in this paper results obtained on the basis of testing in the real world of Social University qualimetric methods for assessing the quality of training practitioners in the system of professional training, in one way or another are consistent with the data presented by a number of researchers (Bulat \& Shadrina, 2010; Karpenko, 2012; Korneshuk \& Rubin, 2009).

Summarizing the foregoing, it can be stated that the implementation of the system of postgraduate education qualimetric methods designed to carry out certain standardized levels of achievement adult learners at the end of a certain stage of learning (i.e., expected to compare the results of specific training course participants with a fixed mandatory minimum content of education development program courses with the requirements of 
formation of competencies, skills to exchange program alumni).

Diagnostics of the level of formation of knowledge, skills and competences of a graduate retraining programs carried out in accordance with the requirements of professional educational standards, as well as the individual qualification requirements that the employer demands to the position occupied or applied for by the listener of the course preparation. Such diagnostics of formation of competences can have the initial, intermediate and final character. In the complex (final) expert opinion on the level of formation of competence, professionally important qualities of the graduate course program, the opportunity to eliminate the deficiencies in the training of the specialist, as well as the possibility of long-term professional and personal development (self-development) of the social worker must be mentioned.

For the final complex peer rewiew about the level of professional training of graduate of retraining programs (over 500 hours) on the basis of the results there should be formed interval scales, which are combined in "the achieved level of professional qualification (i.e. formedness aggregate professional competences) - time (time spent in the course for preparation for the formation of this level)". Note that the time is limited. If the listener of retraining program already has a basic level of development of individual professional competence, the task of optimizing the learning in postgraduate education is to ensure the development of these competencies and their connection with others new ones.

It should be emphasized that in the process of final (comprehensive) assessment of level of development it is important to assess such factor as the "stability of manifestation". With optimization of educational process in the system of postgraduate education, it is necessary to identify the conditions for sustainability of the application of knowledge, skills, competencies, and professional- behavioral stability of training course students in educational and vocational training (internships) processes. All professional competence and their relationship should be stable during its diagnosing for graduates of such programs. But the ideal competence may differ significantly from the real. It is very important to diagnose the stability level course in matters of professional conduct.

\section{Conclusion and Final Considerations}

Implementation of the qualimetric methods in the process of retraining courses can provide clarity, order, sufficient objective data about professional qualification level and professional-personal development degree of each of the adults enrolled in post-graduate education.

It can be asserted that the quality of social workers professional retraining can be achieved with purposeful and constant influence the following subsystems of quality assurance system:

1) Subsystem of planning standard sample quality of certain implementation of training programs (which includes the development of clear, objectively diagnosed characteristics of quality of assimilation by those who are studying the certain vocational education program and the introduction of the plan of step by step implementation of a certain program to the student).

2) Subsystem to establish the functional-dependent communications and the interaction between all the links of a holistic vocational educational process at university, which provides quality of fulfillment of a certain training program (necessary to take into account the specific nature of a particular group, professional and personal characteristics of the collective of teachers, the specific features and a variety of activities: educational, vocational and practical, research, laboratory, consultative, tutorial etc. in the implementation of certain programs, the specifics of didactic and technical facilities to provide the educational process).

3) Subsystem to control the quality of realization of a certain vocational educational program (this subsystem involves providing adequate measurement of certain quality indicators with standardized procedures; data analysis with interpreting the results of control and estimation procedures; amendment the function of various structural units of the holistic educational process in the institution; systematic external peer review of the quality of implementation of training programs).

It should be emphasized that the methods, discussed in this article, we used not only for management of quality of professional training program "Manager of institutions of social protection and social services" (508 hours) and "Management of the organization to provide rehabilitation services to persons with disabilities" (508 hours), but for the program "Modern methods and technologies of professional activity of the social teacher" (502 hours), "Management in education" (528 hours). It is important to note that in this article due to its limited scope, we discuss only some of qualimetric methods developed by the authors. The authors developed a set of interrelated and mutually complementary methods that have been successfully and efficiently implemented to improve the quality of professional training of social workers. 


\section{References}

Abdullah, F. (2006). Measuring service quality in higher education: Three instruments compared. International Journal of Research and Method in Education, 29(1), 71-89. http://dx.doi.org/10.1080/01406720500537445

Andrich, D. (2001). Advanced Social and Educational Measurement. Perth: Murdoch University.

Angell, R. J., Heffernan, T. W., \& Megicks, P. (2008). Service Quality in Postgraduate Education. Quality Assurance in Education, 16(3), 236-254. http://dx.doi.org/10.1108/09684880810886259

Arcaro, J. (1995). Quality in education: An implementation handbook. Delray Beach, Fla: St. Lucie Press.

Avanesov, B. S., Anisimova, T. S., Maslak, A. A. O., Sementsova, A., \& Smirnova, G. I. (2005). Pedagogical dimension, The thesaurus. Educational measurement, 1, 28-32.

Bellingham, L. (2008). Quality Assurance and the Use of Subject Level Reference Points in the UK. Quality in Higher Education, 14(3), 265-276. http://dx.doi.org/10.1080/13538320802507653

Blackmore, J. (2004). A critical evaluation of academic internal audit. Quality in Higher Education, 12(3), 128-135.

Blinkhorn, S. F. (1997). Past imperfect, future conditional: Fifty years of test theory. British Journal of $\begin{array}{llrr}\text { Mathematical } \quad \text { and } & \text { Statistical } & \text { Psychology, } & \text { 50, }\end{array}$ http://dx.doi.org/10.1111/j.2044-8317.1997.tb01139.x

Bloom, B. S. (1956). Taxonomy of educational objectives. In The classification of educational goals (pp. 14-17). New York, NY.: David McKay.

Borges L. F. M., Santos, C. K. S. \& Leal, E. A. (2014). Quality in educational service: Expectations versus performance in the undergraduate accounting course. European Scientific Journal, 10(1), 100-114.

Borrego, M., Douglas, E. P., \& Amelink, C. T. (2009). Quantitative, qualitative, and mixed research methods in engineering education. Journal of Engineering Education, 98(1), 53-66. http://dx.doi.org/10.1002/j.2168-9830.2009.tb01005.x

Brenna, J., \& Shah, T. (2000). Managing Quality in Higher Education: An International Perspective on Institutional Assessment and Change. Buckingham: Open University Press.

Bitusikova, A., Bohrer, J., Borošic, I., Costes, N., Edinsel, K., Holländer, K., ... Mulder, F. (2010). Quality Assurance in Postgraduate Education (p. 12). Workshop Report.

Bulat, R., \& Shadrina, E. (2010). Topical Issues of Personality-Centered Professional Education Quality Manageme. Engineering Education, 6, 32-38.

Cheng, Y. C., \& Tam, W. M. (1997). Multi-models of Quality in Education. Quality Assurance in Education, 5(1), 22-31. http://dx.doi.org/10.1108/09684889710156558

Cizek, G. J. (Ed.). (2001). Setting performance standards: Concepts, methods, and perspectives. Mahwah, NJ: Lawrence Erlbaum Associates.

Cohen, J. W. (1988). Statistical power analysis for the behavioral sciences (2nd ed.). Hillsdale, NJ: Erlbaum.

Colling, C., \& Harvey, L. (1995). Quality assurance and control assessment in the link to continuous improvement. Quality Assurance in Education, 3(4), 30-34. http://dx.doi.org/10.1108/09684889510098168

Cotton, K. (1988). Monitoring Student Learning in the Classroom. Portland, OR: Northwest Regional Educational Laboratory.

Dimas, G., Goula, A., \& Pierrakos, G. (2011). Quality Issues in Higher Education: A Multicriteria Framework of Satisfaction Measures. Creative Education, 2, 305-312. http://dx.doi.org/10.4236/ce.2011.23042

Ehlers, U. D. (2009). Understanding quality culture. Quality Assurance in Education, 17(4), $343-363$. http://dx.doi.org/10.1108/09684880910992322

Faber, K., López, V., \& Prescher, T. (2012). "I learn": Developing a new approach in higher education for lifelong learning. European Journal of Higher Education, 2(2-3), 218-233. http://dx.doi.org/10.1080/21568235.2012.709382

Fomina, N. B. (2011). A new model of quality assessment of education: Pedagogical diagnostics of predictable outcomes of schooling. Directory of Vice Principal, 10, 13-26.

Frazer, M. (1994). Quality in Higher Education: An International Perspective. In D. Green (Ed.), What is Quality 
in Higher Education? Buckingham: SRHE and Open University Press.

Galkina, T. E., \& Nikitina, N. I. (2014). The modern paradigms of quality management of additional professional education of specialists of sociological professions. Sworld, 11(2), 32-41. Retrieved from http://sworld.com.ua/konfer35/531.pdf

Garafutdinova, G. R. (2011). Design technology of qualitative assessment of professional competences of students of technical universities ( $\mathrm{PhD}$ thesis). Kazan State Technological University, Kazan.

Gulliksen, H. (1986). Perspective on Educational Measurement. Applied Psychological Measurement, 10(2), 109-132. http://dx.doi.org/10.1177/014662168601000201

Green, D. (1994). What is quality in higher education? Concept, policy and practice. In D. Green (Ed.), What is quality in higher education? Buckingham: SRHE and Open University Press.

Guilford, J. P. (1956). Fundamental Statistics in Psichology and Education. New York, NY: McGraw-Hill Book Company.

Harvey, L., \& Williams, J. (2010). Fifteen Years of Quality in Higher Education. Quality in Higher Education, 16(1), 3-36. http://dx.doi.org/10.1080/13538321003679457

Juran, J. M. (1988). Quality Control Handbook (Vol. 4). New York, NY: McGraw-Hill.

Karpenko, M. R. (2012). The quality of high education. Moscow: Modern Humanitarian Academy.

Komarova, E. V., \& Nikitina, N. I. (2014). On the implementation in the system of additional professional education of social workers qualimetric approach. Innovations in education, 6, 68-79.

Korneshuk, N. G., \& Rubin, G. Sh. (2009). Qualimetric model of integrated assessment of quality of educational systems. International journal of experimental education, 5, 7-10.

Krasnov A. N., Zhirov, V. V., \& Krasnov Y. A. (2006). Some problems of development of traditional testing technologies for diagnosis of qualities of theoretical training of students of medical clinical disciplines school. In A. I. Subetto, \& N. A. Selezneva (Eds.), Qualimetry in education: methodology, methods, and practice (pp. 18-29). Moscow: Research center of problems of quality of training.

Mechkov, N. A. (2005). Synergetic model of system of remote training health managers and medical managers. Information technology in quality management and innovation management, 1, 73-77.

Medvedeva, L. D. (2009). On the training of specialists of economic profile in the context of globalization. Bulletin of the Tomsk State Pedagogical University, 2, 76-79.

Mikhailychev, E. A. (2001). Didactic testology. Moscow: Publishing house "Narodnoe obrazovanie".

Miller, R. J., \& Rowan, B. (2006). Effects of Organic Management on Student Achievement. American Educational Research Journal, 43(2), 219-253. http://dx.doi.org/10.3102/00028312043002219

Nikitina, N. I., Galkina, T. E., \& Komarova, E. V. (2013). Modeling of the process of implementation of the qualitative approach in the system of additional professional education of social workers. Scientific support to the system of advanced training, 1(14), 54-64.

Owlia, M. S., \& Aspinwall, E. M. (1998). A framework for measuring quality in engineering education. Total Quality Management, 9(6), 501-518. http://dx.doi.org/10.1080/0954412988433

Petersen, N. S., Kolen, M. J., \& Hoover, H. D. (1989). Scaling, norming and equating. In R. L. Linn (Ed.), Educational measurement (3rd ed., pp. 221-262). New York: American Council on Education.

Pospelov, G. S., \& Irikov, V. A. (1976). Target-oriented planning and management. Moscow: Publishing house "Soviet radio".

Richardson, K. E. (1998). Quantifiable feedback: Can it really measure quality? Quality Assurance in Education, 6(4), 212-219. http://dx.doi.org/10.1108/09684889810242218

Safontsev, S. S. (2004). Educational qualimetry as a factor of increasing the efficiency of quality control of studying process ( $\mathrm{PhD}$ thesis). Rostov Institute of Improvement of Professional Skill and Professional Retraining of Educators, Rostov-on-Don.

Shikhov, Y. A. (2008). Designing and implementing of comprehensive quality monitoring of students training in the "profile school-Technical college" ( $\mathrm{PhD}$ thesis). Izhevsk state technical University, Izhevsk.

Soutar, G., \& McNeil, M. (1996). Measuring service quality in a tertiary institution. Journal of Educational Administration, 34(1), 72-82. http://dx.doi.org/10.1108/09578239610107174 
Srikanthan, G., \& Dalrymple, J. (2003). Developing alternative perspectives for quality in higher education. International Journal of Educational Management, 17(3), 126-136. http://dx.doi.org/10.1108/09513540310467804

Subetto, A. I., \& Selezneva, N. A. (1999). Monitoring the quality of continuing education in Russia. Novosibirsk: Publishing house of Novosibirsk State University.

Subetto, A. I. (1993). From qualimetry person-To qualimetry of education. Moscow: Publishing House of the Moscow Institute of Steel Alloys.

Sviridov, A. P. (1981). Fundamentals of statistical teaching theory and knowledge control. Moscow: Publishing House of the "Vysshaya shkola".

\section{Copyrights}

Copyright for this article is retained by the author(s), with first publication rights granted to the journal. This is an open-access article distributed under the terms and conditions of the Creative Commons Attribution license (http://creativecommons.org/licenses/by/3.0/). 